\title{
Alcohol policies and impaired driving in the United States: Effects of driving- vs. drinking-oriented policies
}

\author{
Ziming Xuan ${ }^{1}$, Jason G. Blanchette ${ }^{2}$, Toben F. Nelson ${ }^{3}$, Timothy C. Heeren ${ }^{4}$, Thien H. Nguyen ${ }^{1}$, and \\ Timothy S. Naimi ${ }^{1,2}$ \\ ${ }^{1}$ Department of Community Health Sciences, Boston University School of Public Health, Boston, MA \\ ${ }^{2}$ Section of General Internal Medicine, Boston Medical Center, Boston, MA \\ ${ }^{3}$ Division of Epidemiology and Community Health, University of Minnesota School of Public Health, Minneapolis, MN \\ ${ }^{4}$ Department of Biostatistics, Boston University School of Public Health, Boston, MA
}

\section{Abstract}

Aims: To test the hypotheses that stronger policy environments are associated with less impaired driving and that drivingoriented and drinking-oriented policy subgroups are independently associated with impaired driving.

Design: State-level data on 29 policies in 50 states from 2001-2009 were used as lagged exposures in generalized linear regression models to predict self-reported impaired driving.

Setting: Fifty United States and Washington, D.C.

Participants: A total of 1,292,245 adults ( $\geq 18$ years old) biennially from 2002-2010.

Measures: Alcohol Policy Scale scores representing the alcohol policy environment were created by summing policies weighted by their efficacy and degree of implementation by state-year. Past-30-day alcohol-impaired driving from 2002-2010 was obtained from the Behavioral Risk Factor Surveillance System surveys.

Findings: Higher Alcohol Policy Scale scores are strongly associated with lower state-level prevalence and individual-level risk of impaired driving. After accounting for driving-oriented policies, drinking-oriented policies had a robust independent association with reduced likelihood of impaired driving. Reduced binge drinking mediates the relationship between drinkingoriented policies and impaired driving, and driving-oriented policies reduce the likelihood of impaired driving among binge drinkers.

Conclusions: Efforts to reduce alcohol-impaired driving should focus on reducing excessive drinking in addition to preventing driving among those who are impaired.

In 2010, motor vehicle crashes were the leading cause of unintentional injury death in the U.S. and resulted in 34,000 deaths. Of those, alcohol-impaired crash fatalities (crashes in which blood alcohol concentrations of $\geq 1$ drivers was $\geq$ $0.08 \mathrm{mg} / \mathrm{dl}$ ) accounted for approximately 11,000 deaths (33\% of all crash fatalities) (National Highway Traffic Safety Administration, 2010). In 2010, the total economic cost of fatal and non-fatal alcohol-impaired driving crashes was estimated to be $\$ 125$ billion in the United States (Zaloshnja, Miller, \& Blincoe, 2013).

Alcohol-impaired driving is linked to excessive drinking (Birdsall, Reed, Huq, Wheeler, \& Rush, 2012; Flowers et al., 2008; Naimi, Nelson, \& Brewer, 2009). Despite improvements in vehicle and road safety and the enactment of policies to prevent driving among those who are already impaired, the proportion of crash deaths that are alcoholrelated remained unchanged in the United States since 1995 (Centers for Disease Control and Prevention, 2011; National Highway Traffic Safety Administration, 2010; Voas, Torres, Romano, \& Lacey, 2012). This coincides with a period when some important policies to address alcohol-impaired driving have been implemented, but also when policies to curb excessive drinking have eroded (Hahn et al., 2012; Stehr, 2007; The Center on Alcohol Marketing and Youth, 2006, 2010), and binge drinking and per capita consumption have increased (LaVallee \& Yi, 2012; Naimi et al., 2003).

Correspondence: Timothy S. Naimi. SGIM, Boston Medical Center, 801 Massachusetts Ave., Room 2046, Boston, MA 02118. Telephone: 617-414-6693; E-mail: timothy.naimi@bmc.org

Financial support: Supported by National Institutes of Health grant AA018377. The content and views expressed in this manuscript are those of the co-authors and do not necessarily represent those of the National Institute on Alcohol Abuse and Alcoholism or the National Institutes of Health.

Keywords: Alcohol policy, alcohol-impaired driving, public health law, binge drinking 
Since all states have multiple alcohol policies with various levels of implementation (National Institute of Alcohol Abuse and Alcoholism, 2013), it is important to assess the overall impact on alcohol-impaired driving from the alcohol policy environment, conceptualized as the combined effect of concurrent policies and operationalized as composite policy measures. Furthermore, we hypothesize that the overall policy environment can be conceptually divided into two subgroups, one group consisting of drinking-oriented policies and the other group consisting of driving-oriented policies. Prior research on the effect of individual policies has demonstrated that both driving-oriented policies and drinking-oriented policies can reduce alcohol-impaired driving and alcohol-related crash fatalities (Birckmayer, Boothroyd, Friend, Holder, \& Voas, 2008; Cummings, Rivara, Olson, \& Smith, 2006; Grube \& Stewart, 2004; Popova, Giesbrecht, Bekmuradov, \& Patra, 2009; Rammohan et al., 2011; Wagenaar, Salois, \& Komro, 2009; Wagenaar, Tobler, \& Komro, 2010; WhettenGoldstein, Sloan, Stout, \& Liang, 2000; Williams, 2006). The aims of this study were 1) to test the primary hypothesis that the state overall alcohol policy environment is associated with self-reported impaired driving; 2) to assess whether two policy environment subgroupsdivided theoretically from the overall environment into driving-oriented policies and drinking-oriented policiesare independently associated with impaired driving; 3 ) to explore whether binge drinking mediates the association between state alcohol policy environment and impaired driving; and 4) to ascertain whether the driving-oriented policies moderate the association between binge drinking and impaired driving.

\section{Methods}

\section{Developing Scales to Represent the Policy Environment - Overview}

A detailed description of the development of Alcohol Policy Scale (APS) scores has been published previously (Naimi et al., 2014). Because there was no gold standard by which to develop composite variables to operationalize the policy environment, we engaged a panel of 10 alcohol policy experts (Naimi et al., 2014) using a modified Delphi approach. The policy experts assisted our investigators with three tasks: 1) nominating and selecting existing alcohol policies; 2) rating the relative efficacy of those policies; and 3) developing implementation ratings for each policy.

\section{Policy Selection, Policy Efficacy Ratings}

Forty-seven alcohol control policies were initially nominated by panelists as being effective at reducing excessive alcohol consumption and related harms at the population level (Nelson et al., 2013). Since this was a U.S. study, we excluded policies that did not exist in the United States. We also excluded federal policies, those that did not vary across states, and those without reliable crossstate data. Examples of excluded policies were blood alcohol content (BAC) .05 laws (which do not exist in the United States), restrictions on marketing and mass-media advertising (not promulgated at state level), public intoxication laws (no variance at the state level), and mandatory substance abuse assessment for impaireddriving offenders (absence of reliable data). Policies excluded due to inadequate or missing data tended to have low efficacy ratings (those policies excluded due to inadequate or missing data had a median rank of 32 out of original 47 policies). Ultimately, 29 policies met criteria for inclusion in the policy scale.

Each panelist's efficacy ratings for each policy included four distinct outcome domains: reducing binge drinking among adults, reducing impaired driving among adults, reducing drinking among underage youth, and reducing drinking and driving among youth. Efficacy ratings for reducing impaired driving among adults were used for these analyses. Prior to rating, investigators developed standardized descriptions of each policy. Panelists then independently rated the efficacy of each policy for reducing impaired driving based on 5-point Likert scale $(1=$ low efficacy, 5 = high efficacy) (Naimi et al., 2014; Nelson et al., 2013). Additional detail about the efficacy rating process and average efficacy scores for each policy are summarized in a separate manuscript (Nelson et al., 2013).

\section{Implementation Ratings}

In consultation with panelists with expertise in particular policies, investigators developed an implementation rating based on provisions or characteristics of each particular policy. Factors informing the implementation rating were typically based on a policy's statutory design (i.e., provisions making the policy broadly applicable, effective, or enforceable). The implementation-rating scales were reviewed by all panelists and revised based on their feedback. For all policies, the implementation-rating score for each policy, by state and year, could range from 0.0 (no policy) to 1.0 (full implementation) (Naimi et al., 2014). Implementation-rating criteria applied to each policy were uniform across state-years.

\section{Aggregating Policy Data to Calculate Alcohol Policy Scale Scores}

Several methods were used to aggregate policy data into APS scores for each state-year. Method 1 was based on a summation of one point for each existing policy. Method 2 involved summing the efficacy ratings of all existing policies. Method 3 involved summing the implementation ratings of all existing policies. Methods 4 and 5 involved summing the products of efficacy and implementation ratings of all existing policies. In Method 4 the efficacy ratings were determined directly by rescaling the Likert scale ratings (i.e., [ER-1] / 4), while in Method 5 efficacy ratings were transformed by taking the inverse of their efficacy rank relative to other policies. The approach for Methods 4 and 5 is a commonly utilized aggregation technique in composite indicator literature that involves summing weighted and normalized sub-indicators (Nardo et al., 2005). Scores for all five methods were then divided by their respective maximum possible scores and multiplied by 100 to rescale them within a theoretical range from 0 to 100 . The purpose for this rescaling was to place 
all scores on one scale that would make them comparable across methods. The general formula to calculate the APS scores for methods 4 and 5 is

$$
\text { APS } \text { score }_{j h}=\left\{\left[\sum_{k=1}^{n=29}\left(E R_{k} * I R_{k j h}\right)\right] / M\right\} * 100
$$

where $\mathrm{j}=$ state; $\mathrm{h}$ = year; $\mathrm{k}=$ policy; $\mathrm{ER}$ = efficacy rating; IR = implementation rating; $M=$ Maximum possible score.

\section{Grouping Policies into Drinking- and Driving- Oriented Policy Subgroups}

Alcohol policies were divided into two mutually exclusive groups: drinking-oriented and driving-oriented policies (Appendix 1). Drinking-oriented policies regulate alcohol production, sales, consumption, or furnishing (e.g., alcohol taxes, prohibiting sales to intoxicated patrons). Drivingoriented policies included those that regulate driving and are intended to act by preventing or restricting an already intoxicated person from driving (e.g., blood alcohol content of .08, sobriety checkpoints). APS subgroup scores were calculated for each state-year using the same formula for Method 5.

\section{Data Sources}

For policy data sources, only sources with data for all 50 states and Washington, D.C., that used uniform ascertainment methods across states were included (Naimi et al., 2014). The primary policy data source was the Alcohol Policy Information System (National Institute of Alcohol Abuse and Alcoholism, 2013), which was a source for 14 of the 29 policies and was the primary source for 13 of these policies. Eighteen additional data sources were used to collect and code data about policies and provisions (Naimi et al., 2014).

Investigators reviewed the data for each policy to identify missing or inconsistent data and to identify data that changed briefly before returning to its original form. When multiple data sources were available for a particular policy, we cross-checked data sources for consistency. Discrepancies were resolved by a public health lawyer using the legal research database WestlawNext.

State-level adult impaired driving data during even years of 2002-2010 came from the CDC's Behavioral Risk Factor Surveillance System (BRFSS) survey. Extensive detail about the BRFSS survey and its methods are available at www.cdc.gov/brfss. The BRFSS comprises state-based random-digit dialing telephone surveys of people aged 18 years or older; surveys are conducted monthly in all states, the District of Columbia, and three U.S. territories. Alcohol-impaired driving was defined as reporting one or more episodes of "driving after having had too much to drink" during the past 30 days. Binge drinking was defined as consuming $\geq 5$ (men) or $\geq 4$ (women) drinks on one or more occasions in the past 30 days. Data were weighted to be representative of state populations.
Individual-level covariates included gender, age, race/ethnicity (non-Hispanic White, non-Hispanic Black, Hispanic, and non-Hispanic others, including Asian, Native Hawaiian, or other Pacific Islander, American Indian, or Alaska Native), employment status, marital status (married, not married), level of education ( $<$ high school, high school, or general equivalency diploma, some post-high school, college graduate), and household income (< $\$ 25,000, \$ 25,000-\$ 49,999$, > \$49,999) collected in the BRFSS survey. State-level covariates included state-level demographic characteristics (proportion of adults aged 21 years or older, gender, race/ethnicity), urbanization (proportion of urban population), median household income, religious composition (Catholic adherence rate), police officers per capita, and geographic region (Northeast, Midwest, South, West). Data for these covariates were obtained from several sources (Xuan et al., 2013).

\section{Assessing Relationship between APS Scores and State-level Impaired Driving Prevalence}

For all state-year strata, simple linear regression was conducted using state-year APS scores of each scoring method to predict state-level prevalence of alcoholimpaired driving for all 50 states and Washington, D.C. Goodness-of-fit was evaluated using R-squared. A 1-year lag between the APS exposure variable and impaired driving prevalence outcome was assessed (e.g., APS scores in year $\mathrm{X}$ were associated with impaired driving prevalence in year $X+1)$. To adjust for the clustering of repeated measures of the same state, we also employed the generalized estimating equations (GEE) method to compare to results based on linear regression, as well as longitudinal analysis approach to relate APS scores to the trajectories of state alcohol-impaired driving prevalence.

\section{Relationships between APS Scores and Individual- level Impaired Driving}

A GEE approach was used to assess the bivariate relationship between APS scores and individual-level adult self-reported impaired driving outcomes. Models were constructed by sequentially including individual-level covariates, year, and a number of important state-level covariates in 3 separate models. We also examined the relationship between APS scores and individual-level impaired driving in analyses stratified by year. Because demographic variables contain multiple categories (e.g., race and ethnicity), we conducted stratified analyses by individuals' demographic variables to examine differential associations between policy environment and impaired driving. To explore whether adult binge drinking is a potential mediator, we assessed whether binge drinking attenuates the association between APS score and impaired driving outcomes in the adjusted regression models. To assess the driving-oriented policy subgroup as a potential moderator, we evaluated the interaction term between two continuous predictors of impaired driving (driving-oriented policy scores and binge drinking prevalence).

To assess the relationship between APS scores and adult impaired driving outcomes, the change of odds of adult 
impaired driving was associated with an absolute 10 percentage point difference in the APS scores; this difference was similar to the interquartile range of APS scores among these 255 state-years of data (interquartile range $=10.9$ out of a maximum possible APS score of 100). Similar to state-level analyses, a 1-year lag between the policy exposure variable and drinking outcomes was used in all analyses.

\section{Results}

\section{State Variation in APS Scores}

The alcohol policy environment differed across U.S. states. Using 2009 as an example, Figure 1 shows the distribution of APS scores for all 50 U.S. states and Washington, D.C., using Method 5 (the method that incorporated the policy efficacy ranks and implementation rating). The scores were approximately normally distributed. Montana had the lowest APS score and Oklahoma had the highest APS score.

\section{Relationship between APS Scores and State-Level Impaired Driving Prevalence}

In bivariate analysis, all five methods for calculating the APS score were strongly correlated with one another and inversely associated with impaired driving prevalence among adults for an increase of 10 percentage points in APS scores (e.g., Method 5 beta $=-0.45 ; p<.0001$, Table 1). In bivariate analyses, APS scores calculated by Method 5 explained the greatest proportion of variance of impaired driving $\left(\mathrm{R}^{2}=0.265\right)$ among the five methods. In a model adjusting for state-level covariates, the inverse relationship between the APS score (based on Method 5) and state-level impaired driving prevalence remained highly significant (beta $=-0.21 ; p=.0036$, data not shown).

Similar effect estimates were observed from GEE method (beta $=-0.46 ; p<.0001$ ) that adjusted for the clustering of the repeated measures of the same state over the study period. We also conducted longitudinal analysis relating the change of state-level APS scores to the change in statelevel impaired driving prevalence. Longitudinal analysis yielded consistent unadjusted and adjusted (with covariates) effects of APS (Method 5) scores on impaired driving prevalence for a 10 percentage point increase in APS scores (unadjusted beta $=-0.34 ; p<.0001$; adjusted beta $=-0.20 ; p=.008)$.

Figure 2 shows the correlation between Alcohol Policy Scale scores (based on 29 alcohol policies in 2009) and state alcohol-impaired driving prevalence in 2010.

\section{Figure 1}

Distribution of alcohol policy scale scores, 29 policies, 2009 (State names are abreviated in the graph)

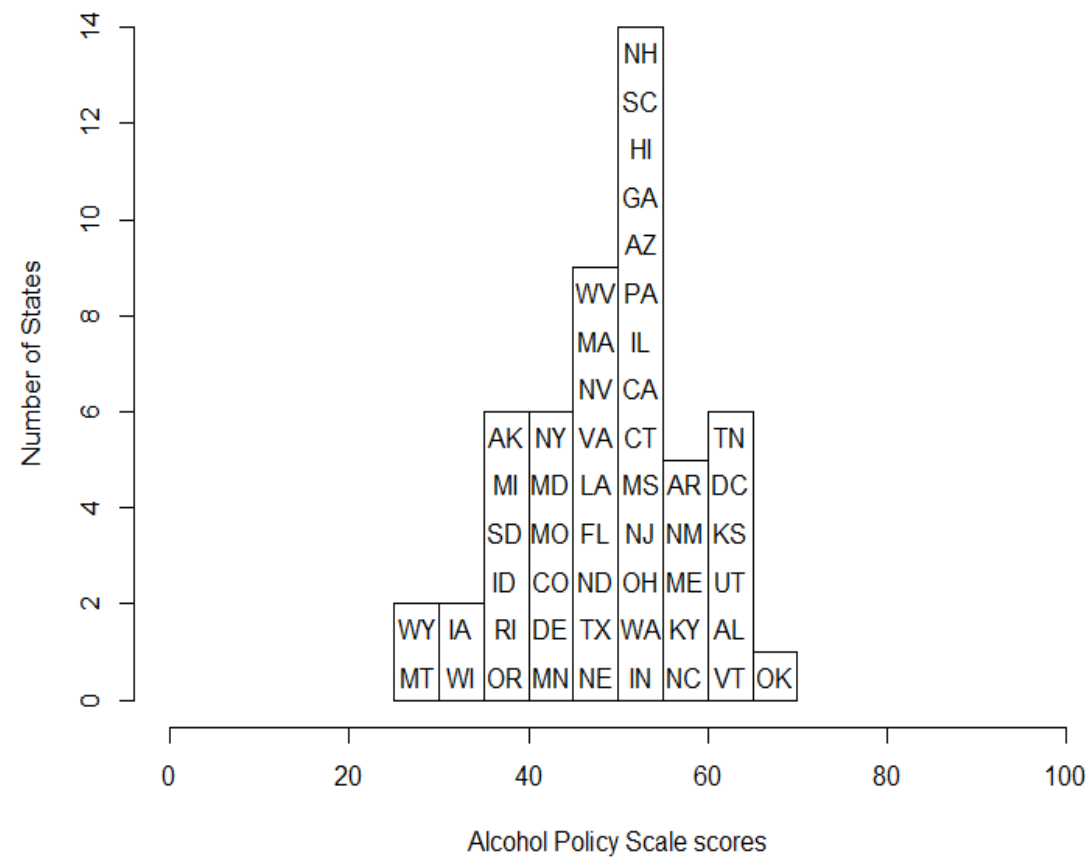


Table 1

Relationship between Alcohol Policy Scale scores and state-level adult impaired driving prevalence $e^{a}$ in the United States, 2002-2010 (even years) ${ }^{b}$

\begin{tabular}{ccccc}
\hline Alcohol Policy Scale Score Method & Beta & $\boldsymbol{S E}$ & $\boldsymbol{P}$ value & $\boldsymbol{R}$-squared \\
\hline $1^{\mathrm{c}}$ & -0.47 & 0.059 & $<.001$ & 0.205 \\
$2^{\mathrm{d}}$ & -0.42 & 0.059 & $<.001$ & 0.168 \\
$3^{\mathrm{e}}$ & -0.53 & 0.061 & $<.001$ & 0.237 \\
$4^{\mathrm{f}}$ & -0.50 & 0.058 & $<.001$ & 0.230 \\
$5^{\mathrm{g}}$ & -0.45 & 0.047 & $<.001$ & 0.265 \\
\hline
\end{tabular}

${ }^{a}$ Alcohol-impaired driving prevalence was obtained from BRFSS surveys and was defined by report of any number above zero in response to the question "During the past month, how many times have you driven when you've had perhaps too much to drink?"

${ }^{\mathrm{b}}$ An absolute 10 percentage point increase in the state Alcohol Policy Scale (APS) score was associated with impaired driving outcomes using a one-year lag between APS scores and alcohol-impaired driving outcomes (APS scores in year X were associated with alcohol-impaired driving prevalence in year $\mathrm{X}+1$ ) in linear regression models.

${ }^{c}$ Method 1 was calculated by summing one point for each existing policy.

${ }^{\mathrm{d}}$ Method 2 was calculated by summing the efficacy ratings of all existing policies in a particular state-year.

${ }^{\mathrm{e}}$ Method 3 was calculated by summing the implementation ratings of all existing policies in a particular state-year.

${ }^{\mathrm{f}}$ Method 4 was calculated by summing the products of implementation and efficacy ratings of all existing policies in a particular state-year after rescaling the efficacy ratings (i.e., [ER-1] / 4).

${ }^{\mathrm{g}}$ Method 5 was calculated by summing the products of implementation ratings and the inverse of the efficacy-rating ranks of all existing policies in a particular state-year.

\section{Figure 2}

Scatterplot of state Alcohol Policy Scale scores and state alcohol impaired driving prevalence

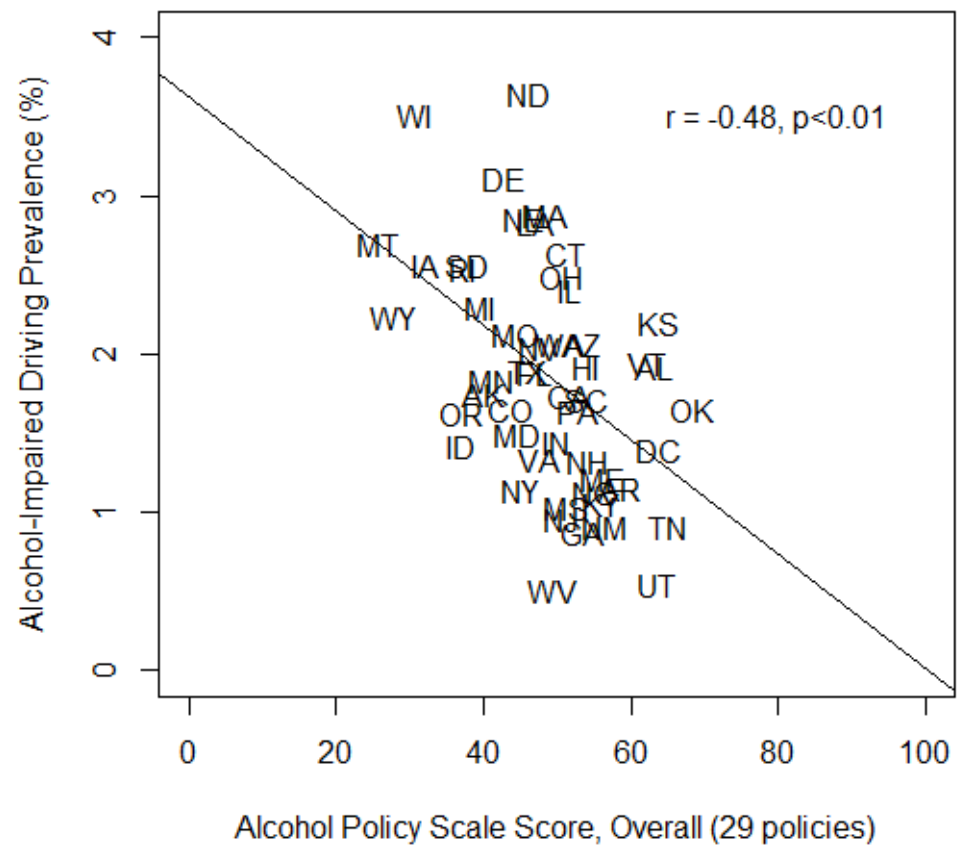

\section{Relationship between APS Scores and Individual- Level Alcohol-Impaired Driving}

An absolute 10 percentage point increase in the APS scores was associated with a 15-20\% reduction in odds of impaired driving according to bivariate analyses (Table 2). After controlling for individual- and state-level covariates and year, a 10 percentage point increase in the APS scores was associated with a $10 \%$ reduction in odds of any impaired driving (adjusted odds ratio $[A O R]$ 0.90; 95\% confidence interval $[\mathrm{CI}]: 0.87,0.93)$ and a $9 \%$ reduction in odds of impaired driving two or more times (AOR 0.91, 95\% CI: 0.87, 0.96).

The association between APS and impaired driving did not differ significantly in analyses stratified by sex and age (Table 3). However, there were significant differences by race and ethnicity. A significantly, inverse association between the APS score and impaired driving prevalence was observed among Non-Hispanic Whites (AOR: 0.88; 95\% CI: 0.85, 0.91), while no significant association was observed among Hispanic, Non-Hispanic Black, or NonHispanic other race groups. 
Table 2

Odds ratios (OR) and 95\% Confidence Intervals (CI) of individual-level U.S. adult alcohol-impaired driving outcomes ${ }^{a}$ associated with a 10 percentage point increase in the state Alcohol Policy Scale score, Behavioral Risk Factor Surveillance System Surveys, 2002-2010 (even years) ${ }^{b}$

\begin{tabular}{|c|c|c|}
\hline & Any Alcohol-Impaired Driving & Alcohol-Impaired Driving $\geq 2$ times \\
\hline Generalized estimating equations (GEE) Models & OR $(95 \% \mathrm{CI})$ & OR $(95 \% \mathrm{CI})$ \\
\hline Bivariate model & $0.78(0.76-0.80)$ & $0.79(0.76-0.82)$ \\
\hline Adjusted model (individual-level ${ }^{\mathrm{c}}$ covariates) & $0.80(0.78-0.82)$ & $0.80(0.77-0.84)$ \\
\hline $\begin{array}{l}\text { Adjusted model (individual-level }{ }^{\mathrm{C}} \text { covariates and } \\
\text { year }^{\mathrm{d}} \text { ) }\end{array}$ & $0.81(0.79-0.83)$ & $0.81(0.78-0.85)$ \\
\hline $\begin{array}{l}\text { Adjusted model (individual }{ }^{\mathrm{c}} \text { - and state-level } \\
\text { covariates, year }^{\mathrm{e}} \text { ) }\end{array}$ & $0.90(0.87-0.93)$ & $0.91(0.87-0.96)$ \\
\hline
\end{tabular}

${ }^{\text {a }}$ Alcohol-impaired driving data were obtained from Behavioral Risk Factor Surveillance System surveys and were defined by self-report of any number above zero in response to the question "During the past month, how many times have you driven when you've had perhaps too much to drink?”

${ }^{\mathrm{b}}$ A one-year lag between the Alcohol Policy Scale (APS) exposure variable and alcohol-impaired driving outcome was assessed (APS scores in year $\mathrm{X}$ were associated with alcohol-impaired driving prevalence in year $\mathrm{X}+1$ ).

${ }^{c}$ Individual-level covariates include sex, age, employment status, race and ethnicity, marital status, level of education, and household income.

${ }^{\mathrm{d}}$ Year is modeled as a categorical variable.

${ }^{\mathrm{e}}$ State-level covariates are proportion of adult (21+) population, sex, race/ethnicity, urbanization, household income, religious composition (percent Catholic adherence), police officers per capita, and geographic region (Northeast, Midwest, South, West).

\section{Table 3}

Adjusted odds ratios (AOR) of individual-level U.S. adult alcohol-impaired driving ${ }^{a}$ associated with a 10 percentage point increase in the state Alcohol Policy Scale score, by selected demographic characteristics, Behavioral Risk Factor Surveillance System Surveys, 2002-2010 (even years) ${ }^{b}$

\begin{tabular}{|c|c|c|}
\hline & Any Alcohol-Impaired Driving & Alcohol-Impaired Driving $\geq 2$ times \\
\hline Demographic Characteristic & $A O R\left(95 \% \mathrm{CI}^{\mathrm{c}}\right)$ & AOR $(95 \% \mathrm{CI})$ \\
\hline \multicolumn{3}{|l|}{ Sex } \\
\hline Male & $0.90(0.87-0.94)$ & $0.92(0.87-0.97)$ \\
\hline Female & $0.88(0.83-0.93)$ & $0.89(0.80-0.99)$ \\
\hline \multicolumn{3}{|l|}{ Age } \\
\hline $18-20$ & $0.90(0.75-1.07)$ & $1.00(0.79-1.25)$ \\
\hline $21-34$ & $0.93(0.88-0.99)$ & $0.92(0.84-1.00)$ \\
\hline $35-64$ & $0.87(0.84-0.91)$ & $0.91(0.85-0.97)$ \\
\hline $65+$ & $0.84(0.74-0.94)$ & $0.74(0.63-0.87)$ \\
\hline \multicolumn{3}{|l|}{ Race and ethnicity } \\
\hline Non-Hispanic White & $0.88(0.85-0.91)$ & $0.91(0.86-0.96)$ \\
\hline Non-Hispanic Black & $1.02(0.84-1.23)$ & $0.84(0.62-1.13)$ \\
\hline Hispanic & $0.87(0.74-1.02)$ & $0.86(0.67-1.10)$ \\
\hline Non-Hispanic Other & $0.97(0.84-1.12)$ & $0.98(0.80-1.20)$ \\
\hline
\end{tabular}

\footnotetext{
${ }^{a}$ Alcohol-impaired driving data were obtained from Behavioral Risk Factor Surveillance System surveys and were defined by self-report of any number above zero in response to the question "During the past month, how many times have you driven when you've had perhaps too much to drink?”

${ }^{\mathrm{b}}$ A one-year lag between the Alcohol Policy Scale (APS) exposure variable and alcohol-impaired driving outcome was assessed (APS scores in year $\mathrm{X}$ were associated with alcohol-impaired driving prevalence in year $\mathrm{X}+1$ ) using generalized estimating equation models. Covariates adjusted in the model include year as a categorical variable, individual-level covariates (sex, age, employment status, race and ethnicity, marital status, level of education, and household income), and state-level covariates [proportion of adult (21+) population, sex, race/ethnicity, urbanization, household income, religious composition (percent Catholic), police officers per capita, and geographic region (Northeast, Midwest, South, West)].

${ }^{\mathrm{C}}$ Confidence intervals.
} 


\section{Policy Subgroups and Alcohol-Impaired Driving} Outcomes

Within states, there was no statistically significant correlation between drinking- and driving-oriented policy subgroups $(r=0.07 ; p=.069$, data not shown). The drinking- and driving-oriented policy subgroups are shown in separate figures (Figures 3 and 4) in relation to the statelevel prevalence of alcohol-impaired driving. After controlling for one another in adjusted models (Table 4), both driving-oriented policies and drinking-oriented policies showed significant inverse associations with individual-level impaired driving ( $A O R$ for drinkingoriented policies 0.94; 95\% CI: 0.91, 0.97; AOR for driving-oriented policies 0.96; 95\% CI: $0.95,0.97)$. There was no significant interaction effect between the drinking- and driving-oriented policy subgroups for impaired driving outcomes.

Does Binge Drinking Mediate the Relationship between Drinking-Oriented Policies and Impaired Driving?

The independent relationship between drinking-oriented policies and impaired driving became non-significant after controlling for state-level binge drinking prevalence (AOR 0.98; 95\% CI: 0.95, 1.01, data not shown), suggesting that binge drinking mediates the relationship between drinkingoriented policies and impaired driving.

Figure 3

Scatterplot between Alcohol Policy Scale driving-subgroup scores and state alcohol-impaired driving prevalence

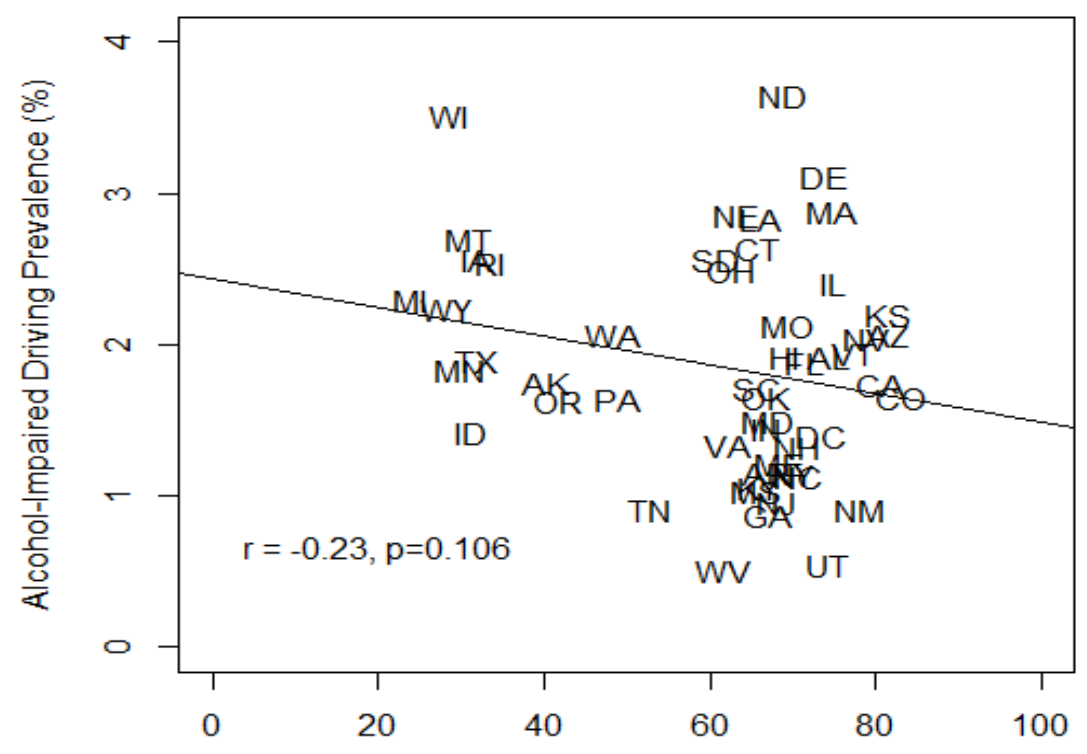

Alcohol Policy Scale Score, Driving-Oriented Policies 


\section{Figure 4}

\section{Scatterplot between Alcohol Policy Scale drinking-subgroup scores and state alcohol-impaired driving prevalence}

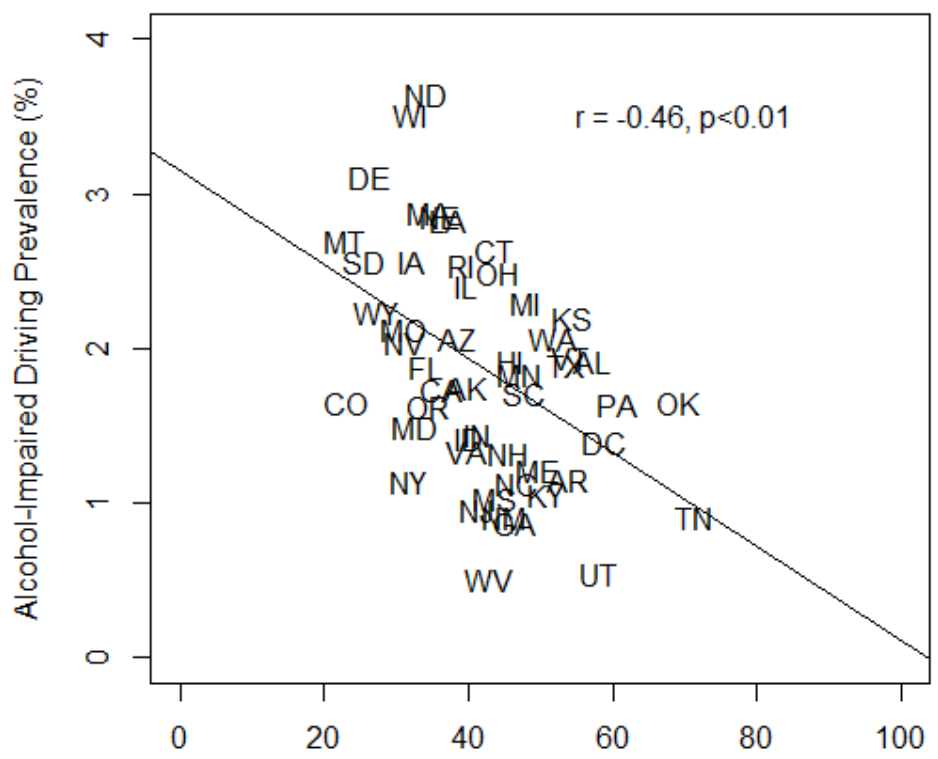

Alcohol Policy Scale Score, Drinking-Oriented Policies

\section{Table 4}

Adjusted odds ratios (AOR) of individual-level U.S. adult alcohol-impaired driving ${ }^{a}$ associated with a 10 percentage point increase in the state Alcohol Policy Scale score for drinking-and driving-oriented policy subgroups, Behavioral Risk Factor Surveillance System Surveys, 2002-2010 (even years) ${ }^{b}$

\begin{tabular}{|c|c|c|}
\hline & Any Alcohol-Impaired Driving & Alcohol-Impaired Driving $\geq 2$ times \\
\hline Policy Group Exposure Variable ${ }^{c}$ & $A O R\left(95 \% \mathrm{CI}^{\mathrm{d}}\right)$ & AOR (95\% CI) \\
\hline \multicolumn{3}{|l|}{ Driving-Oriented Policies $^{\mathrm{e}}$} \\
\hline Model $1^{\mathrm{f}}$ & $0.97(0.96-0.99)$ & $0.95(0.93-0.97)$ \\
\hline Model $2^{f}$ & $0.96(0.95-0.97)$ & $0.95(0.93-0.97)$ \\
\hline \multicolumn{3}{|l|}{ Drinking-Oriented Policies ${ }^{g}$} \\
\hline Model $1^{\mathrm{h}}$ & $0.96(0.94-0.99)$ & $1.01(0.97-1.06)$ \\
\hline Model $2^{\mathrm{h}}$ & $0.94(0.91-0.97)$ & $0.98(0.94-1.02)$ \\
\hline
\end{tabular}

${ }^{a}$ Alcohol-impaired driving data were obtained from Behavioral Risk Factor Surveillance System surveys and were defined by self-report of any number above zero in response to the question "During the past month, how many times have you driven when you've had perhaps too much to drink?”

${ }^{\mathrm{b}}$ A one-year lag between the Alcohol Policy Scale (APS) exposure variable and drinking outcome was assessed (APS scores in year X were associated with alcohol-impaired driving prevalence in year $\mathrm{X}+1$ ) in generalized estimating equation models.

${ }^{\mathrm{c}}$ All models adjusted for year as a categorical variable, individual-level covariates (including sex, age, employment status, race/ethnicity, marital status, level of education, and household income), and state-level covariates [(including proportion of adult (21+) population, sex, race/ethnicity, urbanization, household income, religious composition (percent Catholic), police officers per capita, and geographic region (Northeast, Midwest, South, West)].

${ }^{\mathrm{d}}$ Confidence intervals.

${ }^{\mathrm{e}}$ Driving policies group consisted of policies that are intended to act by preventing or removing an already intoxicated person from driving or can otherwise be viewed as policies that regulate driving. See Appendix 1 for a list of driving-oriented policies.

${ }^{\mathrm{f}}$ Model 1 adjusted for year, individual-level covariates, and state-level covariates. Model 2 adjusted for year, individual-level covariates, statelevel covariates, and drinking-oriented policies.

${ }^{\mathrm{g}}$ Drinking policies group consisted of policies that do not regulate driving or can otherwise be viewed as policies that regulate alcohol production, sales, consumption, or furnishing. See Appendix 1 for list of drinking-oriented policies.

${ }^{\mathrm{h}}$ Model 1 adjusted for year, individual-level covariates, and state-level covariates. Model 2 adjusted for year, individual-level covariates, statelevel covariates, and driving-oriented policies. 


\section{Do Driving-Oriented Policies Moderate the Relationship Between Binge Drinking Status and Impaired Driving?}

Compared to those who reported no binge drinking, the odds of impaired driving was 20.8 times higher among those who reported at least one binge drinking episode ( $p<$ .0001 , data not shown). We found the magnitude of this association to be significantly reduced in states with stronger driving-oriented policy environment (interaction effect between binge drinking status and driving-oriented policies on impaired driving: beta $=-0.005 ; p=.013$ ).

\section{Discussion}

To our knowledge, this is the first comprehensive study of evaluating the relationship between the alcohol policy environment and self-reported alcohol-impaired driving. This study had at least four important findings. First, the alcohol policy environment is protective for alcoholimpaired driving, such that in fully adjusted models a $1 \%$ increase in the policy environment score was associated with an approximate 1\% decrease in impaired driving prevalence. Second, the alcohol policy environment explains a substantial proportion of the variation between states in terms of impaired driving prevalence and frequency. Third, both drinking-oriented and drivingoriented policy subgroups are independently associated with reduced impaired driving. And fourth, binge drinking mediates the relationship between drinking-oriented policies and impaired driving, and driving-oriented policies moderate the relationship between binge drinking and the likelihood of impaired driving. Our findings were similar when using different lag periods between the policy environment and impaired driving outcomes; they were consistent in individual years as well as for all years combined; they were similar in state- and individual-level analyses; and they were consistent when using different statistical models that account for clustering of repeated measures of the same state over time (i.e., GEE models, longitudinal models).

Our findings showed a possible mediating mechanism where reduced binge-drinking prevalence could explain the relationship between stronger alcohol policy environments and lower likelihood of impaired driving. More stringent policies likely reduce binge drinking, and reduced binge drinking could lower the number of alcohol-impaired persons who may engage in impaired driving. Furthermore, stronger policies can lower alcohol consumption; as a result, relatively lower blood alcohol content among those who are impaired could facilitate better judgment and further reduce the likelihood of deciding to drive under the influence of alcohol.

Although the alcohol policy environment is conceptualized as the combined effect of multiple concurrent policies and operationalized as composite policy measures, prior work has shown that alcohol taxes strongly predict binge drinking among adults and youth (Xuan et al., 2013), and the most effective policies, such as alcohol taxation and outlet density, accounted for approximately half of the effect magnitude observed for all policies in predicting adult binge drinking (Xuan et al., 2015). Therefore, increasing alcohol taxes and restricting outlet density can effectively enhance state alcohol policy environments and likely reduce impaired driving by reducing excessive alcohol consumption. A $10 \%$ increase in strength among state alcohol policy environments in all states would result in about 404,903 fewer impaired drivers monthly, based on a national survey that found 4,049,035 past-month impaired drivers during 2010 (Centers for Disease Control and Prevention, 2011).

Furthermore, although the likelihood of impaired driving is substantially higher among binge drinkers compared to those who reported no binge drinking, we found that the driving-oriented policy environment moderates such relationships (e.g., where stronger driving policies reduced the likelihood of driving under the influence of alcohol even among those who reported binge drinking). This finding is consistent with our expectation. For instance, in states where sobriety checkpoints are conducted, the awareness of possible apprehension and penalty might reduce the likelihood of binge drinkers to drive a motor vehicle after impairment.

Relationships between policy environment and impaired driving appear to be consistent within sex and age groups but different across race/ethnicity factors, which is a finding similar to prior work examining the relationship between policy environment and adult binge-drinking measures (Xuan et al., 2014). In these studies, we observed no statistically significant relationships among nonHispanic Black or Hispanic participants. Relative to nonHispanic Whites, both Black and Hispanic adults have lower alcohol consumption; therefore, we may have omitted potential factors that may have accounted for differential effects on the basis of race and ethnicity. Further investigation is warranted.

We are aware of two studies that have examined the overall effect of multiple policies on alcohol-impaired driving or alcohol-related crash fatalities in the United States (Cohen, Mason, \& Scribner, 2002; Shults et al., 2001). A crosssectional study by Shults et al. (2001) found an inverse relationship between an eight-component report card of drinking and driving countermeasures and self-reported impaired driving in states (Shults et al., 2001). A study of local alcohol policies and alcohol-related crash fatalities by Cohen et al. (2002) assessed latent factors extracted from 20 alcohol policies and regulations using a cross-sectional survey of Alcohol Beverage Control (ABC) agencies and local police departments in 97 cities(Cohen et al., 2002). Compared to cities with $>15$ regulations, those with $<9$ regulations had 1.46 times the rate of alcohol-related crash deaths per vehicle mile travelled. Per capita beer consumption was identified as a potential mediator between policies and alcohol-related crash fatalities.

In previous work, we found that policy environment scale scores (based on efficacy ratings for reducing binge drinking rather than impaired driving) were strongly 
associated with reduced binge drinking among adults in U.S. states (Naimi et al., 2014). The similar findings between the two studies underscore the hand-in-glove relationship between binge drinking and impaired driving (Birdsall et al., 2012; Centers for Disease Control and Prevention, 2011; Flowers et al., 2008). As such, it was not surprising to see that drinking-oriented policies had an independent and slightly stronger inverse relationship with impaired driving relative to driving-oriented policies. It is important to note that there are fewer driving-oriented policies than drinking-oriented policies, which may partly explain this finding. On the other hand, having more available policies to reduce drinking reflects policy reality in the United States and represents an important opportunity for impaired driving prevention. This is especially true since states have not enacted policies to reduce excessive drinking at the same level as those policies intended to reduce driving among people who are already impaired (e.g., based on the APS scores for the drinking- versus driving-oriented policy subgroups in states as illustrated in Figures 3 and 4). In other words, in most states there is a greater opportunity for improvement in terms of adopting and aggressively implementing drinkingoriented policies, although there is a great need to strengthen driving-oriented policies as well.

This study is subject to caveats and limitations. Taken alone, our finding is largely associative in nature and conclusions about causality must be tempered. However, while it is possible that public opinion supporting more restrictive alcohol and driving policies may be driving the outcomes rather than the policies themselves, comprehensive reviews of effective alcohol and impaired driving policies have been based primarily on longitudinal analyses in which the effect of policy is assessed after the policy is enacted, thus controlling for prevalent attitudes that led to adoption of those policies in the first place (Campbell et al., 2009; Elder et al., 2010; Hahn et al., 2010; Middleton et al., 2010; Rammohan et al., 2011; Shults et al., 2001). There is strong evidence from other studies that implementing effective policies lead to changes in alcohol consumption and related outcomes.

The purpose of this study was to assess effects of state policies. The policy scales did not include policies that are promulgated at the national, county, or local levels (e.g., alcohol marketing in mass media, county-level alcohol taxes). In addition, some policies nominated as effective did not have reliable cross-state data about their presence or provisions and were therefore not included in our APS scoring system. We also acknowledge that the efficacy ratings and implementation ratings for any given policy may be informed by an incomplete and limited evidence base and that a different group of investigators or policy panelists might have differing opinions about what constitutes key provisions of a given policy (Nardo et al., 2005).

Enforcement is a theoretically important component of policy implementation for some policies (Ritter, 2007), but there are no reliable, publicly available cross-state data about enforcement, even for specific policies. We addressed this limitation by including policy provisions that made particular policies enforceable, by including the number of ABC officials with enforcement capability as an alcohol policy in our scales, and by controlling for the number of police officers per capita as a state-level control variable. However, all limitations related to the imprecision of the exposure or outcome variables may have attenuated our findings and likely biased the results towards the null hypothesis. BRFSS estimates are subject to survey non-coverage and non-response biases but are reliable for comparisons across states, which was the focus of our analyses (Nelson, Naimi, Brewer, \& Roeber, 2010; Paschall, Ringwalt, \& Gitelman, 2010).

At last it should be noted that the BRFSS began to use a gender-specific definition of binge drinking (5 drinks for men, 4 drinks for women) in 2006. The change of definition likely changed the binge drinking prevalence among women. However, it is unlikely the change in the binge drinking definition altered the overall findings in this study, because the majority of binge drinkers are men, and the relationships between policy environment and binge drinking were similar between men and women (Xuan et al., 2014).

Despite these limitations, the development of the APS establishes the groundwork for further studying the effect of the alcohol policy environment in the United States and for subsequently assessing the relative impacts of combinations of related policies for reducing alcoholrelated mortality outcomes, including alcohol-related driving fatalities.

Overall, our findings support the importance of comprehensive alcohol policies as an effective means to reduce alcohol-impaired driving and further indicate that strengthening drinking-oriented policies (e.g., increasing alcohol taxes) is a critical component of an overall policy approach.

\section{References}

Birckmayer, J. D., Boothroyd, R. I., Friend, K. B., Holder, H. D., \& Voas, R. B. (2008). Prevention of alcoholrelated motor vehicle crashes: Logic model documentation. Retrieved from http://www.pire.org/ documents/Alc_rel_MV_crashes.doc

Birdsall, W. C., Reed, B. G., Huq, S. S., Wheeler, L., \& Rush, S. (2012). Alcohol-impaired driving: Average quantity consumed and frequency of drinking do matter. Traffic Injury Prevention, 13(1), 24-30.

Campbell, C. A., Hahn, R. A., Elder, R., Brewer, R., Chattopadhyay, S., Fielding, J., . . . Middleton, J. C. (2009). The effectiveness of limiting alcohol outlet density as a means of reducing excessive alcohol consumption and alcohol-related harms. American Journal of Preventive Medicine, 37(6), 556-569.

Centers for Disease Control and Prevention. (2011). Vital signs: Alcohol-impaired driving among adults United States, 2010. Morbidity and Mortality Weekly Report, 60(39), 1351-1356. 
Cohen, D. A., Mason, K., \& Scribner, R. (2002). The population consumption model, alcohol control practices, and alcohol-related traffic fatalities. Preventive Medicine, 34(2), 187-197.

Cummings, P., Rivara, F. P., Olson, C. M., \& Smith, K. M. (2006). Changes in traffic crash mortality rates attributed to use of alcohol, or lack of a seat belt, air bag, motorcycle helmet, or bicycle helmet, United States, 1982-2001. Injury Prevention, 12(3), 148-154.

Elder, R. W., Lawrence, B., Ferguson, A., Ferguson, A., Naimi, T. S., Brewer, R. D., . . . The Task Force on Community Preventive Services. (2010). The effectiveness of tax policy interventions for reducing excessive consumption and related harms. American Journal of Preventive Medicine, 38, 217-229.

Flowers, N. T., Naimi, T. S., Brewer, R. D., Elder, R. W., Shults, R. A., \& Jiles, R. (2008). Patterns of alcohol consumption and alcohol-impaired driving in the United States. Alcoholism: Clinical and Experimental Research, 32, 639-644.

Grube, J. W., \& Stewart, K. (2004). Preventing impaired driving using alcohol policy. Traffic Injury Prevention, 5(3), 199-207.

Hahn, R. A., Kuzara, J. L., Elder, R., Brewer, R., Chattopadhyay, S., Fielding, J., . . . Lawrence, B. (2010). Effectiveness of policies restricting hours of alcohol sales in preventing excessive alcohol consumption and related harms. American Journal of Preventive Medicine, 39(6), 590-604.

Hahn, R. A., Middleton, J. C., Elder, R., Brewer, R., Fielding, J., Naimi, T. S., . . Campbell, C. A. (2012). Effects of alcohol retail privatization on excessive alcohol consumption and related harms: A community guide systematic review. American Journal of Preventive Medicine, 42(4), 418-427.

LaVallee, R. A., \& Yi, H.-Y. (2012). Surveillance report \#95: Apparent per capita alcohol consumption: National, state, and regional trends, 1977-2010. Bethesda, MD, United States: National Institute on Alcohol Abuse and Alcoholism.

Middleton, J. C., Hahn, R. A., Kuzara, J. L., Elder, R., Brewer, R., Chattopadhyay, S., . . . Lawrence, B. (2010). Effectiveness of policies maintaining or restricting days of alcohol sales on excessive alcohol consumption and related harms. American Journal of Preventive Medicine, 39(6), 575-589.

Naimi, T. S., Blanchette, J., Nelson, T. F., Nguyen, T., Oussayef, N., Heeren, T. C., . . . Xuan, Z. (2014). A new scale of the U.S. alcohol policy environment and its relationship to binge drinking. American Journal of Preventive Medicine, 46(1), 10-16.

Naimi, T. S., Brewer, R. D., Mokdad, A. H., Denny, C., Serdula, M., \& Marks, J. S. (2003). Binge drinking among U.S. adults. The Journal of the American Medical Association, 289, 70-75.

Naimi, T. S., Nelson, D. E., \& Brewer, R. D. (2009). Driving after binge drinking. American Journal of Preventive Medicine, 37(4), 314-320.

Nardo, M., Saisana, M., Saltelli, A., Tarantola, S., Hoffman, A., \& Giovannini, E. (2005). Handbook on constructing composite indicators: Methodology and user guide. Paris, France: Organisation for Economic Co-operation and Development Publishing.

National Highway Traffic Safety Administration. (2010). Traffic safety facts 2009: A compilation of motor vehicle crash data from the Fatality Analysis Reporting System and the General Estimates System. Early Edition. Retrieved from http://wwwnrd.nhtsa.dot.gov/Pubs/811402EE.pdf

National Institute of Alcohol Abuse and Alcoholism. (2013). Alcohol Policy Information System. Retrieved from www.alcoholpolicy.niaaa.nih.gov/ (electronic database).

Nelson, D. E., Naimi, T. S., Brewer, R. D., \& Roeber, J. (2010). U.S. state alcohol sales compared to survey data, 1993-2006. Addiction, 105, 1589-1596.

Nelson, T. F., Xuan, Z., Babor, T., Chaloupka, F. J., Gruenewald, P., Holder, H., . . . Naimi, T. S. (2013). Rating the efficacy and strength of evidence of alcohol control policies for the U.S.: A comparative assessment. American Journal of Preventive Medicine, 45(1), 19-28.

Paschall, M. J., Ringwalt, C. L., \& Gitelman, A. M. (2010). The validity of state survey estimates of binge drinking. American Journal of Preventive Medicine, 39(2), 179-183.

Popova, S., Giesbrecht, N., Bekmuradov, D., \& Patra, J. (2009). Hours and days of sale and density of alcohol outlets: Impacts on alcohol consumption and damage: A systematic review. Alcohol and Alcoholism, 44(5), 500-516.

Rammohan, V., Hahn, R. A., Elder, R., Brewer, R., Fielding, J., Naimi, T. S., . . . Zometa, C. (2011). Effects of dram shop liability and enhanced overservice law enforcement initiatives on excessive alcohol consumption and related harms: Two community guide systematic reviews. American Journal of Preventive Medicine, 41(3), 334-343.

Ritter, A. (2007). Comparing alcohol policies between countries: Science or silliness? PLOS Medicine, 4(4), e153.

Shults, R. A., Elder, R. W., Sleet, D. A., Nichols, J. L., Alao, M. O., Carande-Kulis, V. G., ... Thompson, R. S. (2001). Reviews of evidence regarding interventions to reduce alcohol-impaired driving. American Journal of Preventive Medicine, 21(4S), 6688.

Stehr, M. (2007). The effect of Sunday sales bans and excise taxes on drinking and cross-border shopping for alcoholic beverages. National Tax Journal, 60(1), 85105.

The Center on Alcohol Marketing and Youth. (2006). Striking a balance: Protecting youth from overexposure to alcohol ads and allowing alcohol companies to reach the adult market. Retrieved from http://www.camy.org/research/Striking_a_Balance_Pr otecting_Youth_From_Overexposure_to_Alcohol_Ad s_and_Allowing_Alcohol_Companies_to_Reach_the_ Adult_Market/index.html

The Center on Alcohol Marketing and Youth. (2010). Youth exposure to alcohol advertising on television, 2001-2009. Retrieved from http://www.camy.org/ 
research/Youth_Exposure_to_Alcohol_Ads_on_TV_ Growing_Faster_Than_Adults/index.html

Voas, R. B., Torres, P., Romano, E., \& Lacey, J. H. (2012). Alcohol-related risk of driver fatalities: An update using 2007 data. Journal of Studies on Alcohol and Drugs, 73(3), 341-350.

Wagenaar, A. C., Salois, M. J., \& Komro, K. A. (2009). Effects of beverage alcohol price and tax levels on drinking: A meta-analysis of 1003 estimates from 112 studies. Addiction, 104, 179-190.

Wagenaar, A. C., Tobler, A. L., \& Komro, K. A. (2010). Effects of alcohol tax and price policies on morbidity and mortality: A systematic review. American Journal of Public Health, 100(11), 2270-2278.

Whetten-Goldstein, K., Sloan, F. A., Stout, E., \& Liang, L. (2000). Civil liability, criminal law, and other policies and alcohol-related motor vehicle fatalities in the United States: 1984-1995. Accident Analysis \& Prevention, 32(6), 723-733.
Williams, A. F. (2006). Alcohol-impaired driving and its consequences in the United States: The past 25 years. Journal of Safety Research, 37(2), 123-138.

Xuan, Z., Blanchette, J. G., Nelson, T. F., Heeren, T. C., Oussayef, N., \& Naimi, T. S. (2015). The alcohol policy environment and policy subgroups as predictors of binge drinking measures among US adults. American Journal of Public Health, 105(4):816-822.

Xuan, Z., Nelson, T. F., Heeren, T., Blanchette, J., Nelson, D. E., Gruenewald, P., \& Naimi, T. (2013). Tax policy, adult binge drinking, and youth alcohol consumption in the United States. Alcoholism: Clinical and Experimental Research, 37(10), 17131719.

Zaloshnja, E., Miller, T. R., \& Blincoe, L. (2013). Costs of alcohol-involved crashes: United States. Annals of Advances in Automotive Medicine, 57, 3-12.

\section{Appendix 1}

\section{Policies in the alcohol policy scale scores, by policy orientation}

\begin{tabular}{ll}
\hline Drinking-oriented policies & Driving-oriented policies \\
\hline Taxes & Sobriety checkpoints \\
State control/monopoly & Blood alcohol content limit of .08 \\
Wholesale-price restrictions & Administrative license revocation \\
Outlet density & Ignition interlocks \\
Dram shop liability & Open container in automobiles \\
Retail-price restrictions & Use/lose laws \\
Hours of sale & Zero tolerance \\
Alcohol beverage control agencies & Graduate drivers licensing \\
Sales to intoxicated patrons prohibited & \\
Responsible beverage service training & \\
Social host civil liability & \\
Days of sale & \\
Local option & \\
Minimum legal drinking age laws & \\
Minimum age of server/seller & \\
House party & \\
Direct shipment to consumers & \\
Keg registration & \\
Furnishing alcohol to minors & \\
Fetal alcohol syndrome warning signs & \\
Fake ID laws & \\
\hline
\end{tabular}

